\title{
Editorial
}

\section{Turf Wars in Radiology: Need to Introspect!!}

\author{
Ankur Shah ${ }^{1}$ \\ ${ }^{1}$ Consultant Radiologist, Sadbhav Imaging Centre, Ahmedabad, India \\ Indian J Radiol Imaging 2021;31:795-796.
}

India is considered as the best example of Unity in Diversity, and the same implies to our fraternity with a large variety of sub-specialties and imaging modalities. Radiology and all the work related to radiology have been very close to our heart, whether it is radiographs, ultrasound, CT scan, MRI, PET-CT or Interventional procedures and we as radiologists always feel that it's only our right to use these modalities.

A lot has been discussed about Turf erosion, that is, our colleagues from other medical disciplines obtaining training and expertise of various radiological modalities and in turn, we, radiologists have to compete with not just other radiologists but also with specialists of other medical disciplines for our work.

As a Radiologist, it is our responsibility to maintain selfinterest, interest of our fellow colleagues and future generations, to inculcate true value of our branch, zeal of constant learning so that this wonderful art of radiodiagnosis keeps on attracting the best brains of the medical profession. At the same time, it is worthwhile to look into the mirror and introspect as to why this situation arose and kept on worsening over the years?

If we go back to the era of radiographs and conventional radiography procedures, radiology was largely considered to be a non-emergency specialty. With the advent of ultrasound, CT scan, MRI and increasing scope of these imaging modalities, radiology has become the heart of medical profession and an integral part of multi-disciplinary team for managing most clinical scenarios. Thereby arose the need for radiologists to work beyond their 'office hours' along with their 'other specialty' colleagues to ensure optimal patient management.

Despite this, many a times we opt not to work in emergency hours. Has this attitude of ours, forced or helped other specialists to take over Radiology work? Had we been up at midnight to perform and report every radiograph of a patient of trauma, every ultrasound of a patient of obstetrics or renal colic, every CT scan or MRI of a recently operated patient, would the other specialists have stayed away from radiology? We do not have a specific answer to this but this attitude of ours could be a reason that led other specialists to learn and gain expertise in radiodiagnostic modalities.

Now is the time to look into the future and see what can be done to prevent further intrusions. The first and foremost need is to gain expertise in our own field. Most super specialty examinations have questions related to radiology now. It is a part of their curriculum to read the CT scan and MRI related to their specialty. Therefore, by the time they start practicing, they are well versed with the modality for areas related to their specialty. We need to keep ourselves a notch ahead. Now, when so many subspecialty fellowships are available in our country and even ICRI is going to start the sub-specialty fellowship programs, it is very much important to train ourselves in specific areas of Radiology, so that we understand the clinical perspective of our radiology reports \& findings and guide the referring clinicians for better management of the patient.

We need to come out of our comfort zones of 3 years of Radiology postgraduate learning and start practicing. Now it's time to spend a minimum of a year or two extra to learn the subject in depth.

There are so many subspecialty fields in Radiology that demand our focus; one such example is musculoskeletal (MSK) interventions. Many of us are doing biopsies, which are far more difficult and carry some risk of complications, but we refrain from doing a simple injection in a joint under ultrasound guidance, because we have not trained ourselves for it. These procedures are ultimately done by an orthopedic surgeon or a pain physician - with or without guidance. These blind injections run the risk of suboptimal results in comparison from procedures performed under image guidance by a trained professional.

This also adds to the satisfaction of directly helping to cure the patient's ailment and helps to increase the patient's confidence in Radiology and Radiologists. When we can create our identity in society as a treating consultant and not just an Imagiologist or Sonologist, it helps to open the
Address for correspondence Ankur Shah, DMRE, Consultant Radiologist, Sadbhav Imaging Centre, Ahmedabad, India 380006

(e-mail: drankur203@gmail.com).
DOI https://doi.org/ 10.1055/s-0042-1742726. ISSN 0971-3026.
(C) 2022. Indian Radiological Association. All rights reserved.

This is an open access article published by Thieme under the terms of the Creative Commons Attribution-NonDerivative-NonCommercial-License, permitting copying and reproduction so long as the original work is given appropriate credit. Contents may not be used for commercial purposes, or adapted, remixed, transformed or built upon. (https://creativecommons.org/ licenses/by-nc-nd/4.0/)

Thieme Medical and Scientific Publishers Pvt. Ltd., A-12, 2nd Floor, Sector 2, Noida-201301 UP, India 
door of ethical practice without any referring charges. We can become front line clinical radiologists and also establish a multidisciplinary interventional team, to gain patient trust. Interaction with the patient is the ultimate key to establish this practice.

\section{Change in Attitude}

We need to be clinical radiologists. We have to be available, accessible and patient centric. We cannot survive in a vacuum by sitting in isolation in our reporting room.

As a clinical radiologist, we cannot limit ourselves to interpreting and diagnosing films or images. We have to analyze images with due consideration of in-depth clinical details and try to answer all pertaining clinical questions. It does not end here. Detailed follow-up, clinical feedback as well as pathology correlation are all important.

We need to encourage clinical meetings, tumor board meetings and multidisciplinary meetings for better patient care. This will bring a satisfaction of being part of a clinical team and more importantly avoid that "vacuum" of lack of clinical touch.

\section{Optimize the Use of Infrastructure}

$24 \times 7$ availability of clinical radiologists in all types of healthcare sector is a must. With the establishment of PACS and super-fast internet connection, we can easily manage most of the emergency work. Although tele-radiology is the largest supportive network for us, we should strongly refrain from using it as a substitute for being there in the department.

\section{Building Future}

We have to encourage fellowships/dedicated training programs for sub-specialty.

Now it is high time to work towards uniformity of language, reporting templates and structured reporting at pan India level to make our reports more clinically relevant and more beneficial for patient management.

We need to put more efforts into encouraging research and data analysis, which is completely ignored by most practicing radiologists in private centers.

With the help of engineers and information technology (IT) companies, we need to learn how our patient data can be used for research in proper ways.

Training of radiographers and CT scan/MRI technicians should also be patient-centric along with learning of advanced imaging technologies.

In the era of growing artificial intelligence (AI), we need to learn how it can be used to ease our workflow and enhance the reporting standards. AI should be seen as a helping tool rather than a threat or competitor to radiologists. It can help to save our time and utilize it in more productive work that is beneficial in patient care.

Lastly, the way imaging technology has been shifting from disruptive to evolving and sustaining, we need to be patient centric, more communicative, and proactive and we have to stand tall for our fraternity by introspecting first. 